\title{
History of depression as a risk factor for dementia: an updated review
}

\author{
Anthony F. Jorm
}

\begin{abstract}
Objective: This review updates an earlier meta-analysis of the data on history of depression as a risk factor for dementia. It also considers the available evidence on the hypotheses proposed to explain the association between history of depression and dementia.

Method: A meta-analysis was carried out on results from seven case-control and six prospective studies. A qualitative review was carried out on the evidence related to the hypotheses to explain the association.

Results: The meta-analysis found evidence to support an association from both casecontrol studies (estimated relative risk $2.01 ; 95 \% \mathrm{Cl} 1.16-3.50$ ) and prospective studies (estimated relative risk 1.87; 95\% Cl 1.09-3.20). However, the evidence did not clearly support any one hypothesis explaining the association. The most likely contenders are: (i) depression can be an early prodrome of dementia, (ii) depression brings forward the clinical manifestation of dementing diseases, and (iii) depression leads to damage to the hippocampus through a glucocorticoid cascade.

Conclusions: The possibility that history of depression is a risk factor for dementia needs to be taken seriously and explanations of the association need to be further researched.

Key words: Alzheimer's disease, dementia, depression, risk factors, vascular dementia.
\end{abstract}

\section{Australian and New Zealand Journal of Psychiatry 2001; 35:776-781}

This paper updates an earlier review on history of depression as a risk factor for dementia [1]. Since the publication of this review, a number of new studies have come out. These add further evidence that history of depression is a risk factor, and have implications for the plausibility of various hypotheses to explain the association.

\section{An up-dated meta-analysis}

A Medline search up to the end of 2000 was carried out using the same specifications as used previously [1]. This search looked for case-control studies (in which people with dementia and controls are assessed retrospectively for a history of depression) and prospective studies (in which people with or without a history of

\footnotetext{
Anthony F. Jorm, Director
}

Centre for Mental Health Research, Australian National University, Canberra 0200, Australia. Email: anthony.jorm@anu.edu.au

Received 13 July 2001; accepted 16 July 2001. depression are followed over time to see if they develop dementia). The search produced one additional casecontrol study and one additional prospective study. These have been added to the studies identified earlier and summarized in Tables 1 and 2. Meta-analyses using the graphical 'odd man out' technique [16] gave the summary estimates of relative risk shown at the bottom of each table. Prospective studies are methodologically superior to case-control studies, but the results from the two sorts of studies were consistent. From these metaanalyses, we can conclude that a history of depression approximately doubles the risk of developing dementia.

These findings raise the question of whether it is the risk of Alzheimer's disease, vascular dementia, or both, that is increased. Most of the case-control studies dealt with Alzheimer's disease specifically, whereas most of the prospective studies dealt with dementia in general. However, because in Western countries most cases of dementia are due to Alzheimer's disease, it is fair to conclude that risk of Alzheimer's disease is increased by a history of depression. Only one study has looked 
Table 1. Case-control studies examining history of depression as a risk factor for dementia

\begin{tabular}{|c|c|c|}
\hline Study & Diagnosis of cases & $\begin{array}{l}\text { Estimate of relative risk } \\
\qquad(95 \% \mathrm{Cl})\end{array}$ \\
\hline EURODEM [2] & Alzheimer's & $1.82(1.16-2.86)$ \\
\hline Speck et al. [3] & Alzheimer's & $1.8(0.9-3.5)$ \\
\hline Cooper \& Holmes [4] & Dementia & $2.31(1.16-4.62)$ \\
\hline Wetherell et al. [5] & Alzheimer's & $4.00(0.64-25.16)$ \\
\hline Agbayewa [6] & Alzheimer's & $2.77(0.61-12.54)$ \\
\hline Steffens et al. [7] & Alzheimer's & $2.08(1.22-3.52)$ \\
\hline Zalsman et al. [8] & Dementia & $1.94(0.98-3.84)$ \\
\hline Summary estimate & - & $2.01(1.16-3.50)$ \\
\hline
\end{tabular}

Table 2. Prospective studies examining history of depression as a risk factor for dementia

\begin{tabular}{|c|c|c|c|}
\hline Study & Diagnosis of cases & Years of follow-up & Estimate of relative risk $(95 \% \mathrm{Cl})$ \\
\hline Buntinx et al. [9] & Dementia & $1-10$ & $2.38(1.08-5.06)$ \\
\hline Devanand et al. [10] & Dementia (mainly Alzheimer's) & $1-5$ & $2.05(1.16-3.62)$ \\
\hline Henderson et al. [11] & Dementia & 3.6 & $0(0-5.5)$ \\
\hline Chen et al. [12] & Alzheimer's & 4 & $1.28(0.51-3.20)$ \\
\hline Palsson et al. [13] & Dementia & 3 & $1.5(0.8-2.9)$ \\
\hline Kessing et al. [14] $]^{*}$ & Dementia & 21 & $13.7(12.1-15.4)$ \\
\hline Geerlings et al. [15] & Alzheimer's & 3.2 & $2.21(1.09-4.48)$ \\
\hline Summary estimate & - & - & $1.87(1.09-3.20)$ \\
\hline
\end{tabular}

specifically at whether history of depression increases risk of vascular dementia [17]. In a prospective study spanning 5 years, history of depression was found to increase the risk of developing vascular dementia by 2.41 times (95\% CI 1.22-4.52). However, further analysis showed that the risk was highest in people who had a previous stroke, so that depression may simply be a marker of the effects of an earlier stroke. Whether depression per se increases risk of vascular dementia needs further research.

As well as studies examining depression as a risk factor for depression, there are prospective studies looking at whether depression symptom scores predict subsequent decline on cognitive tests. The earlier review summarized four of these studies, with only one of them showing a significant association [1]. Since then, two other studies of this type have been published. One study found that depressive symptoms predicted cognitive decline in men but not in women [18], whereas the other found an effect in people with a higher level of education but not in those with a lower level [15]. Unfortunately, it is not possible to carry out a meta-analysis of these results because of the diverse ways in which they have been reported. However, it can be concluded that, while there are more significant results than expected by chance, the findings are far from consistent.

\section{Specific depressive symptoms predicting dementia}

In addition to the above studies on history of depression as a risk factor for dementia or cognitive decline, two studies have looked at individual depressive symptoms as risk factors. One prospective study assessed depressive symptoms and then followed up participants over 3 years [19]. Those who developed Alzheimer's disease were more likely to have 'motivational symptoms' of depression at baseline, but not 'mood symptoms'. These motivational symptoms were lack of interest, loss of energy and concentration difficulties. A second prospective study following participants over an average of 3.2 years found that subjective slowing of thinking and depressed mood were the only symptoms to predict subsequent Alzheimer's disease, but these associations were only found in those with a higher level of education [20]. The results of these two studies are not entirely compatible. While subjective slowing of thinking might be a 'motivational symptom', depressed mood clearly is 
not. It is therefore uncertain from the limited evidence available whether a specific pattern of depressive symptoms is associated with subsequent dementia.

\section{Six hypotheses explaining the association}

The meta-analysis results lead to the conclusion that depression is likely to be a risk factor. In the previous review, six hypotheses to explain the association were put forward. Since then, some additional evidence has appeared with implications for the viability of some of these hypotheses.

\section{Depression treatments are a risk factor for dementia}

Depression could appear to be a risk factor for dementia if treatments used for depression such as antidepressants, benzodiazepines and electroconvulsive therapy (ECT) led to increased risk. However, the earlier review found little support for this hypothesis and there is no new evidence to alter this conclusion.

\section{Depression and dementia share common risk factors}

Depression and dementia could also appear to be linked if they shared common risk factors. However, the commonly acknowledged risk factors for depression show little overlap with those for Alzheimer's disease and vascular dementia. The only exception is that preexisting vascular disease is associated with increased risk of vascular dementia and may also increase risk of depression, since depression is more common in people with disabling physical diseases of any type.

\section{Depression is a prodrome of dementia}

There are clinical observations that people initially diagnosed with depression progress on to clear dementia. These observations suggest that depression may be a prodrome in some cases of dementia. The hypothesis of depression as a prodrome is most compatible with studies in which depression occurs close in time to the onset of dementia. However, because the pathological changes of dementing diseases can begin decades before dementia onset [21], it is also conceivable that depression could be a very early prodromal feature. Two possible mechanisms by which depression could be a prodrome have been proposed: one involving Alzheimer's disease and the other vascular dementia.

If depression was a prodrome of Alzheimer's disease, we might expect that older people who are depressed will tend to have more subclinical Alzheimer neuropathology. However, this does not appear to be the case [22].
Nevertheless, it is still possible that depression could be a prodrome in a minority of cases of Alzheimer's disease. A possible mechanism involves loss of noradrenergic neurones, which is a variable feature of Alzheimer's disease and is associated with comorbid depression [23]. However, for noradrenergic neuronal loss to account for prodromal depression, it would need to be an early neuropathological change in Alzheimer's disease, whereas it is most likely to be found in the later stages of dementia [24].

A second possibility is that depression is a prodrome of vascular dementia. It has been proposed that some cases of depression in old age are due to cerebrovascular disease and that this disease may not be clinically evident when the depression first appears [25]. Supporting evidence comes from MRI studies on depression in old age which show a higher prevalence of white matter changes thought to reflect cerebrovascular disease [26]. These lesions also tend to be associated with cognitive impairments [26] and one prospective study found that depressed patients with white matter changes were more likely to progress to vascular dementia [27]. While these findings support the possibility that depression could be a prodrome of vascular dementia, a difficulty is that the epidemiological evidence is more consistent with depression as a risk factor for Alzheimer's disease. However, there is now some evidence that vascular factors may have a role in Alzheimer's disease as well [28].

\section{Depression occurs as an early reaction to cognitive decline}

Another hypothesis is that people with dementing diseases show early insight into their failing capacities and react to this loss with depression [29]. Most studies do in fact find that people who complain of poor memory or cognitive decline are more likely to develop dementia, although the predictive power of such complaints is weak [30-34]. There is also much evidence showing a strong relationship between cognitive complaints and depressive symptoms, although much of this association is probably due to depression leading to a negative evaluation of cognitive performance rather than to an awareness of cognitive decline leading to depression [34].

The key prediction of this hypothesis is that depression should no longer be a risk factor once the effect of cognitive complaints is statistically controlled. One prospective study did find that the association of depressive symptoms with subsequent dementia disappeared once cognitive complaints were statistically controlled, but subjects with clinical depression were unfortunately excluded from the analysis [33]. More recently, the 
hypothesis was properly tested in two prospective studies and the effect of depression as a risk factor was found to persist even when complaints were statistically controlled [25]. If confirmed by other research, these results would rule out the hypothesis that depression occurs as an early reaction to cognitive decline.

\section{Depression brings forward the clinical manifestations of dementing diseases}

Alzheimer's disease and vascular dementia can be viewed as parts of a continuous pathological spectrum involving various degrees of neuronal loss. There may be a long preclinical phase, with clinically evident dementia occurring once some threshold of neuronal loss is reached. Thus, risk factors for dementia may affect either the rate of neuronal loss or the point where the threshold is reached [35]. It has been hypothesized that individuals who have a larger brain reserve may be better able to compensate for neuronal loss and so manifest dementia at a later stage of pathology [36]. This hypothesis explains findings that individuals who are better educated, more intelligent and with larger brains may have a lower risk of Alzheimer's disease, because all these factors are indicators of brain reserve.

The same hypothesis can be extended to account for depression as a risk factor for dementia. Depression may not affect the pathological processes involved in Alzheimer's disease or vascular dementia, but rather the threshold for manifesting dementia. Depression is well known to involve significant cognitive deficits [37]. These may cumulate with those caused by dementing diseases to bring forward the clinical manifestation of dementia. Depression also involves motivational deficits which may add to those caused by a dementing disease. Such cumulative effects might also be seen in individuals who have a history of depression, but are not currently clinically depressed, because remitted depression is associated with residual cognitive deficits [38].

The key prediction of this hypothesis is that depression will be related to earlier diagnosis and should be a stronger risk factor in studies based on clinical series. Furthermore, individuals with dementia and a history of depression should have less brain pathology when they reach the threshold of clinical recognition. These predictions remain to be tested.

\section{Depression leads to damage to the hippocampus through a glucocorticoid cascade}

Sapolsky and colleagues [39] have put forward a 'glucocorticoid cascade' hypothesis which provides a potential link between depression and dementia. According to this hypothesis, the brain stimulates the adrenal cortex to secrete glucocorticoids in response to stressors. Glucocorticoid secretion prepares the body for coping with the stressor by increasing circulating energy substrates. There are receptors in the hippocampus which detect the increased level of glucocorticoids and inhibit their further secretion. Although secretion of glucocorticoids helps to cope with stressors, prolonged secretion has ill effects, including toxic effects on the hippocampus. With ageing, there is loss of glucocorticoid receptors in the hippocampus. This loss leads to impaired feedback inhibition of glucocorticoid secretion and further damage to the hippocampus, setting off a cascade effect.

Most of the evidence to support this hypothesis has come from animal studies. However, there has been some work on humans. Lupien et al. [40] measured cortisol levels in elderly people over a five-year period and related this to memory performance and hippocampal volume. They found that people with high and rising cortisol levels over the five years had poorer memory performance and greater hippocampal atrophy.

Although the participants in this study did not have either clinical depression or dementia, implications have been drawn for an association of depression with dementia [41]. Hypersecretion of cortisol and nonsuppression in the dexamethasone suppression test have been reported as more common in both depression and dementia. Furthermore, atrophy of the hippocampus is one of the early brain changes in Alzheimer's disease [42] and has also been observed in some depressed patients [43]. These observations have led to the proposal that depression and dementia represent two different time points along a continuum of disease induced by the hypothalamic-pituitary-adrenal (HPA) axis [41]. Depression is hypothesized to lead to increased cortisol levels and prolonged exposure to cortisol leads to hippocampal atrophy and cognitive deficits. When the hippocampal atrophy is severe enough, the person will qualify for a diagnosis of dementia. Unfortunately, there is little evidence directly testing this hypothesis and what evidence does exist is not entirely supportive. No association has been reported between HPA axis disregulation and hippocampal atrophy in depressed patients $[44,45]$. Only one small study has followed up depressed patients with and without hippocampal atrophy over time. This study found that atrophy did not predict either dementia or cognitive decline over a two-year period [46].

In summary, there are correlational data linking depression, cortisol hypersecretion, hippocampal atrophy and dementia, although the predicted correlations are not always found. However, a direct causal pathway from depression and cortisol hypersecretion to hippocampal atrophy and dementia has not been demonstrated and requires further research. 


\section{Conclusion}

The accumulated evidence reinforces the earlier conclusion [1] that depression is a likely risk factor for dementia in general and for Alzheimer's disease specifically. The association with vascular dementia requires more investigation before a conclusion can be reached. Of the six hypotheses to explain the association, three appear to be the most plausible: (i) depression can be an early prodrome of dementia, (ii) depression brings forward the clinical manifestation of dementing diseases, and (iii) depression leads to damage to the hippocampus through a glucocorticoid cascade. These hypotheses are not mutually exclusive and more than one could be correct.

If depression is a risk factor for dementia, this raises the issue of whether preventive action can be taken. However, treating depression is unlikely to be preventive under most of the hypotheses considered. Only the hypothesis of hippocampal damage through a glucocorticoid cascade predicts a preventive effect of depression treatment.

\section{References}

1. Jorm AF. Is depression a risk factor for dementia or cognitive decline? A review. Gerontology 2000; 46:219-227.

2. Jorm AF, van Duijn CM, Chandra V et al. Psychiatric history and related exposures as risk factors for Alzheimer's disease: a collaborative re-analysis of case-control studies. International Journal of Epidemiology 1991; 20:S43-S47.

3. Speck CE, Kukull WA, Brenner DE et al. History of depression as a risk factor for Alzheimer's disease. Epidemiology 1995; 6:366-369.

4. Cooper B, Holmes C. Previous psychiatric history as a risk factor for late-life dementia: a population-based case-control study. Age and Ageing 1998; 27:181-188.

5. Wetherell JL, Gatz M, Johansson B, Pedersen NL. History of depression and other psychiatric illness as risk factors for Alzheimer disease in a twin sample. Alzheimer Disease and Associated Disorders 1999; 13:47-52.

6. Agbayewa MO Earlier psychiatric morbidity in patients with Alzheimer's disease. Journal of the American Geriatrics Society 1986; 34:561-564.

7. Steffens DC, Plassman BL, Helms MJ, Welsh-Bohmer KA, Saunders AM, Breitner JC. A twin study of late-onset depression and apolipoprotein E epsilon 4 as risk factors for Alzheimer's disease. Biological Psychiatry 1997; 41:851-856.

8. Zalsman G, Aizenberg D, Sigler M, Nahshony E, Karp L, Weizman A. Increased risk for dementia in elderly psychiatric inpatients with late-onset major depression. Journal of Nervous and Mental Disease 2000; 188:242-243.

9. Buntinx F, Kester A, Bergers J, Knottnerus JA. Is depression in elderly people followed by dementia? A retrospective cohort study based in general practice. Age and Ageing 1996; 25:231-233.

10. Devanand DP, Sano M, Tang M-X et al. Depressed mood and the incidence of Alzheimer's disease in the elderly living in the community. Archives of General Psychiatry 1996; $53: 175-182$
11. Henderson AS, Korten AE, Jacomb PA et al. The course of depression in the elderly: a longitudinal community-based study in Australia. Psychological Medicine 1997; 27:119-129.

12. Chen P, Ganguli M, Mulsant BH, DeKosky ST. The temporal relationship between depressive symptoms and dementia: a community-based prospective study. Archives of General Psychiatry 1999; 56:261-266.

13. Palsson S, Aevarsson O, Skoog I. Depression, cerebral atrophy, cognitive performance and incidence of dementia. British Journal of Psychiatry 1999; 174:249-253.

14. Kessing LV, Mortensen PB, Bolwig TG. Clinical consequences of sensitisation in affective disorder: a case register study. Journal of Affective Disorders 1998; 47:41-47.

15. Geerlings MI, Schoevers RA, Beekman ATF et al. Depression and risk of cognitive decline and Alzheimer's disease. British Journal of Psychiatry 2000; 176:568-575.

16. Walker AM, Martin-Moreno JM, Artalejo FR. Odd man out: a graphical approach to meta-analysis. American Journal of Public Health 1988; 78:961-966.

17. Hebert R, Lindsay J, Verreault R, Rockwood K, Hill G, Dubois M-F. Vascular dementia. incidence and risk factors in the Canadian Study of Health and Aging. Stroke 2000; 31:1487-1493.

18. Cervilla JA, Prince M, Joels S, Mann A. Does depression predict cognitive outcome 9-12 years later? Evidence from a prospective study of elderly hypertensives. Psychological Medicine 2000; 30:1017-1023.

19. Berger A-K, Fratiglioni L, Forsell Y, Winblad B, Backman L. The occurrence of depressive symptoms in the preclinical phase of AD: a population-based study. Neurology 1999; 53:1998-2002.

20. Geerlings MI, Schmand B, Braam AW, Jonker C, Bouter LM, Van Tilburg W. Depressive symptoms and risk of Alzheimer's disease in more highly educated older people. Journal of the American Geriatrics Society 2000; 48:1092-1097.

21. Braak H, Braak E. Frequency of stages of Alzheimer-related lesions in different age categories. Neurobiology of Aging 1997; 18:351-357.

22. Thomas AJ, Ferrier IN, Kalaria RN, Perry RH, Brown A, O'Brien JT. A neuropathological study of vascular factors in late-life depression. Journal of Neurology Neurosurgery and Psychiatry 2001; 70:83-87.

23. Zubenko GS. Neurobiology of major depression in Alzheimer's disease. International Psychogeriatrics 2000; 12:217-230.

24. Förstl H, Burns A, Luthert P, Cairns N, Lantos P, Levy R. Clinical and neuropathological correlates of depression in Alzheimer's disease. Psychological Medicine 1992; 22:877-884.

25. Alexopoulos GS, Meyers BS, Young RC, Campbell S, Silbersweig D, Charlson M. 'Vascular depression' hypothesis. Archives of General Psychiatry 1997; 54:915-922.

26. O'Brien HJT, Ames D, Schweitzer I. White matter changes in depression and Alzheimer's disease: a review of magnetic resonance imaging studies. International Journal of Geriatric Psychiatry 1996; 11:681-694.

27. Hickie I, Scott E, Wilhelm K, Brodaty H. Subcortical hyperintensities on magnetic resonance imaging in patients with severe depression: a longitudinal evaluation. Biological Psychiatry 1997; 42:367-374.

28. Skoog I. Vascular aspects of Alzheimer's disease. Journal of Neural Transmission 2000; 59:37-43.

29. Bassuk SS, Berkman LF, Wypij D. Depressive symptomatology and incident cognitive decline in an elderly community sample. Archives of General Psychiatry 1998; 55:1073-1081.

30. Tobiansky R, Blizard R, Livingston G, Mann A. The Gospel Oak Study stage IV. the clinical relevance of subjective memory impairment in older people. Psychological Medicine 1995; 25:779-786. 
31. Johansson B, Allen-Burge R, Zarit SH. Self-reports on memory functioning in a longitudinal study of the oldest old: Relation to current, prospective, and retrospective performance. Journal of Gerontology: Psychological Sciences 1997; 52:P139-P146.

32. Schofield PW, Marder K, Dooneief G, Jacobs DM, Sano M, Stern Y. Association of subjective memory complaints with subsequent cognitive decline in community-dwelling elderly individuals with baseline cognitive impairment. American Journal of Psychiatry 1997; 154:609-615.

33. Schmand B, Jonker C, Hooijer C, Lindeboom J. Subjective memory complaints may announce dementia. Neurology 1996; 46:121-125.

34. Jorm AF, Christensen H, Korten AE, Jacomb PA, Henderson AS Memory complaints as a precursor of memory impairment in older people: a longitudinal analysis over 7-8 years. Psychological Medicine 2001; 31:441-449.

35. Mortimer JA. Do psychosocial risk factors contribute to Alzheimer's disease? In: Henderson, AS, Henderson, JH, eds. Etiology of Dementia of Alzheimer's Type. Chichester: John Wiley, 1988; 39-52.

36. Schofield P. Alzheimer's disease and brain reserve. Australasian Journal on Ageing 1999; 18:10-14.

37. Christensen H, Griffiths K, Mackinnon A, Jacomb PA. A quantitative review of cognitive deficits in depression and Alzheimer-type dementia. Journal of the International Neuropsychological Society 1997; 3:631-651.

38. Kessing LV. Cognitive impairment in the euthymic phase of affective disorder. Psychological Medicine 1998; 28:1027-1038.

39. Sapolsky RM, Krey LC, McEwen BS. The neuroendocrinology of stress and aging: the glucocorticoid cascade hypothesis. Endocrine Reviews 1986; 7:284-301.

40. Lupien S, Leon M, de Santi S et al. Cortisol levels during human aging predict hippocampal atrophy and memory deficits. Nature Neuroscience 1998; 1:69-73.

41. Lupien S, Nair NPV, Briere S et al. Increased cortisol levels and impaired cognition in human aging: implication for depression and dementia in later life. Reviews in Neurosciences 1999; 10:117-139.

42. Jack CR, Peterson RC, Xu YC et al. Prediction of AD with MRIbased hippocampal Volume in mild cognitive impairment. Neurology 1999; 52:1397-1403.

43. Sheline YI, Sanghavi M, Mintun MA, Gado MH. Depression duration but not age predicts hippocampal Volume loss in medically healthy women with recurrent major depression. Journal of Neuroscience 1999; 19:5034-5043.

44. Shah PJ, Ebmeier KP, Glabus MF, Goodwin GM. Cortical grey matter reductions associated with treatment-resistant chronic unipolar depression: controlled magnetic resonance imaging study. British Journal of Psychiatry 1998; 172:527-532.

45. O'Brien JT, Ames D, Schweitzer I, Colman P, Desmond P, Tress B. Clinical and magnetic resonance imaging correlates of hypothalamic-pituitary-adrenal axis function in depression and Alzheimer's disease. British Journal of Psychiatry 1996; 168:679-687.

46. Swann A, O'Brien J, Ames D, Schweitzer I, Desmond P, Tress B. Does hippocampal atrophy on MRI predict cognitive decline? A prospective follow-up study. International Journal of Geriatric Psychiatry 1997; 12:1182-1188. 